International medical practices

\title{
The modernisation of general practice in the UK: 1980 to 1995 and beyond. Part I
}

Steve Iliffe

\begin{abstract}
Summary
The UK is unusual in providing universal free healthcare in which access to specialists is largely controlled by general practitioners with 24-hour responsibility, throughout the year, for a defined list of patients of all ages. It is generally considered that this gatekeeper function has contributed to the relatively low cost of the National Health Service, but major changes in the organisation and clinical role of general practitioners have occurred, culminating in a new contract that aims to re-orientate general practice towards health promotion, disease prevention and the management of chronic disease. The implications of these changes are discussed.
\end{abstract}

Keywords: general practice, healthcare management

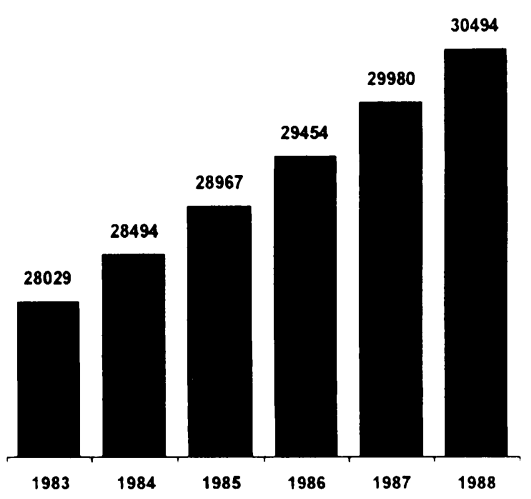

Figure 1 Growth in the GP workforce $1983-8$.

Department of Primary Health Care, University College London Medical School, Whittington Hospital (Archway Site), London N19 5NF, UK

S Iliffe
In the UK primary healthcare services are those which provide citizens with both an initial point of contact with the National Health Service (NHS) and on-going medical care in or near the home. Primary care in most places has three sources: general practitioners (GPs) and their teams; community health services; and some departments with community outreach functions in most Trust Hospitals.

Community health services include child health and family planning doctors, district nurses, health visitors, chiropodists and remedial therapists, some of whom may form part of a wider primary care team through attachment to general practices. As a measure of relative activity, in any one day around 650000 patients are seen by GPs compared with 100000 who are visited by nurses and other health professionals in the community. ${ }^{1}$

Hospital departments with a primary care function include accident and emergency and genito-urinary units, open-access facilities (especially in paediatrics) and outreach programmes, particularly for mental healthcare and care of the elderly. The division of responsibility and the distribution of clinical tasks between the three components of primary care changed significantly throughout the 1980 s, creating possibilities and problems for the professionals working in them. This review focuses on developments in general practice, and its prospects for the future.

The UK is unusual in providing universal free healthcare in which access to specialists is largely controlled by GPs with 24-hour responsibility, throughout the year, for a defined list of patients of all ages. It is generally considered that this gatekeeper function has contributed to the relatively low cost of the NHS, which by the late 1980 s was spending less than half as much per head of population on healthcare as the US, and only two thirds of the amount spent in Sweden. ${ }^{2}$ Around $97^{\circ}$ of the UK population is registered with a GP and only a small proportion change practices unless they move to another location.

\section{Recent developments}

The 1980s was the decade of modernisation in general practice. During the late 1970 s and early 1980 s, general practice became a more attractive career option for doctors, as hospital practice became more bureaucratic and cash limited and the working conditions of junior hospital doctors attracted adverse publicity. The number of doctors entering the GP career path increased steadily throughout the 1980s (figure 1 ). ${ }^{2}$

This recruitment to general practice produced a younger workforce with more women doctors than ever before. Considerable increases in the numbers of GPs occurred in every age band up to 44 , with women doctors constituting nearly a third of those under 35 compared with $9^{\circ}{ }_{0}$ of those aged 65 or over. ${ }^{2}$ These new entrants tended to work in growing group practices, so that by 1988 one in five GPs were working in groups of six or more doctors, compared with $10^{\circ}{ }_{0}$ in 1978 and $4{ }^{\circ}$ in $1968 .^{3}$ The development of group practice was most marked in affluent semi-rural areas like Wessex and Oxfordshire, where nearly a third of GPs were working in large groups. ${ }^{2}$ This development seemed to occur because demographic changes - particularly population movements - put pressure on GPs to expand their services, whilst the availability of greenfield sites for new premises and of relatively low-cost ancillary labour permitted such expansion. ${ }^{4}$ In urban areas, particularly in the inner city areas, development occurred when strong professional leadership co-existed with supportive Family Practitioner Committees.

As the number of GPs increased, the average list size fell (figure 2). ${ }^{2}$ This reduction permitted an increase in average consultation time for seven to nine minutes during the $1980 \mathrm{~s}$. By 1990 the proportion of consultations lasting 10 minutes or more had increased to $25^{\circ}{ }^{\circ}$, compared with $18^{\circ}{ }^{\prime}$, in 1986 . Dedicated clinics for ante-natal care, child health surveillance and the management of 


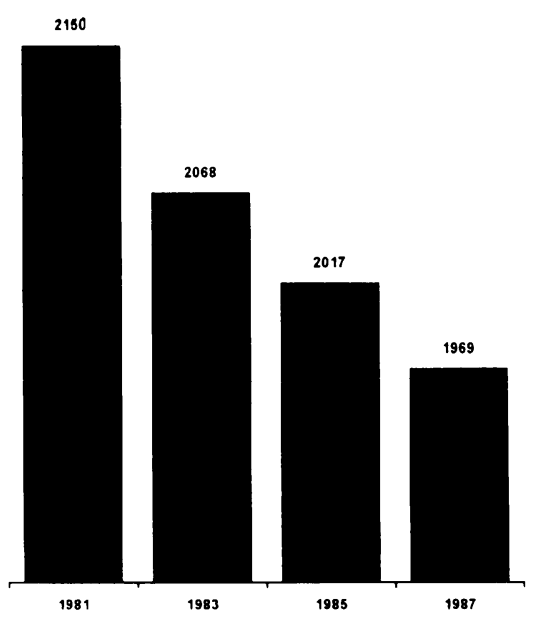

Figure 2 Average GP list size 1981-7.

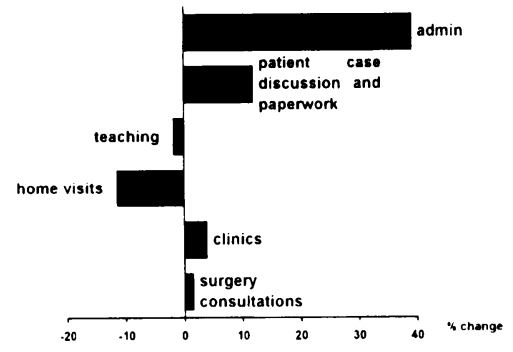

Figure 3 Changes in GP workload 1985/6 to $1989 / 90$. chronic diseases had become established in general practice, and their consultation times were nearer 12 minutes by the end of the decade. ${ }^{5}$

As more time was given to individual patients, more time was also demanded by other aspects of practice activity. By 1990, an average GP was working. 65 hours a week (not counting medico-political activity and continuing professional education), just under 24 of these hours being on call. This represented a $7 \%$ increase in the clinical working week, but a $3 \%$ reduction in on-call time, compared with the middle of the decade. ${ }^{5}$

Factors affecting workload included the sex of the doctor (male general practitioners working longer hours than their female colleagues), the availability of equipment, such as computers, glucometers and peak flow meters, access to physiotherapy, and organisation in a group. ${ }^{5}$ In short, modernisation of general practice, in both organisational and clinical senses, appeared to lead to higher workloads for GPs. However, not all of this increase in workload was attributable to changes in clinical activity and the content of the lengthened consultation. It appears that GPs compensated for a $39 \%$ increase in time devoted to practice administration by reducing time devoted to home visiting and teaching (figure 3 ). The number of GP home visits remained unchanged despite falling list sizes, suggesting that home visits became briefer.

One casualty in this reorganisation of working time and priorities was maternity care. In the early 1980 s $25 \%$ of GPs were involved in intra-partum care. ${ }^{6}$ Now the proportion is less than $10 \%$ and falling ${ }^{7}$ and some question whether there is a future for general practice obstetrics at all. ${ }^{8}$

The number of consultations per patient per year appeared to increase slightly during the middle of the decade, but the average figures conceal major changes in specific age groups. For example, the proportion of children under five seeing a GP in a given time period had doubled in 10 years, to eight consultations per year in 1987. Likewise, there had been a shift in the provision of family planning services to young women, with a $25 \%$ increase in numbers between 1978 and 1987 and a concomitant reduction in attendance at family planning clinics provided by community health services, so that by 1987 about $70 \%$ of contraceptive care was being provided in general practice. ${ }^{2}$

GPs appeared to respond to this increasing workload with a number of strategies, so that by the end of the 1980 s there was a small reduction in the total number of general medical consultations, and only the numbers seen in dedicated clinics (for chronic medical conditions, or for maternity care and child health) remained unchanged. ${ }^{5}$ In 1990 an average GP would have 118 sugery consultations and 22 home visits each week, compared with 124 consultations and 26 home visits five years earlier. Those providing dedicated clinics saw 12 people in them each week in 1990, compared with nearly 13 in the middle of the decade. ${ }^{5}$

It appears that the trend first documented in the 1970s for GPs to have fewer patient contacts per episode of illness ${ }^{9}$ had continued, and that re-orientation of clinical work towards chronic disease management and prevention care might have reduced GPs' daytime availability for the management of acute illnesses. Two pieces of evidence support this view: the increase in out-of-hours activity in accident and emergency departments; and the increase in night calls in general practice.

Use of accident and emergency departments have doubled between 1961 and 1983 , and continued to rise throughout the $1980 \mathrm{~s}^{10,11}$ There was also evidence that accident and emergency departments were providing nearly half of first patient contacts in some urban areas. ${ }^{12}$ Night calls in general practice also appeared to have increased during the 1980 s, with a rate of 10 per 1000 registered patients in 1976, to 15.5 (albeit in one district) in 1981. Large variations occurred in the rate of night visits, with different small-scale studies in the 1980 s showing from 14 to 35 night calls per 1000 patients per year. ${ }^{13}$ However, some of this increase may reflect demographic change rather than changes in the provision of GP care. The proportion of households with a telephone increased from $75 \%$ in 1981 to nearly $90 \%$ in 1990 , whilst social support of groups with high levels of morbidity may have decreased. For example, elderly people living alone increased from $22 \%$ of households in 1981 to $26^{\circ} \%$ in 1991 , whilst single parents with small children increased from $2 \%$ to $4 \%$ of households in the same time. ${ }^{14}$

\section{Modernisation and its problems}

This modernisation created a range of problems for GPs, which were to become issues of public concern and government attention during the decade. The policy agenda for general practice in the 1980s included the problems of primary care in the inner cities and other deprived areas, prescribing policies and practices, ${ }^{15}$ the use of microcomputers, regulation of commercial deputising services, and GP referrals to specialists. There was also some conflict over the best route for 
development of nursing in primary care, with the growth of practice nurses and 'nurse practitioners' on the one hand and the publication of the Cumberledge Report, advocating the independence of community nurses from GPs, on the other. ${ }^{16}$ This raised wider wissues about teamwork, and the definition of the primary care team became the object of considerable discussion.

\section{DEPRIVATION AND HEALTH}

Deprivation leads to greater demands for healthcare which may be inadequately met by local health services, ${ }^{17}$ and social attributes like being unemployed, ${ }^{18}$ being a member of an ethnic minority, ${ }^{19}$ and being in a single parent family ${ }^{20}$ all have an effect on GP workload, especially on out-of-hours care..$^{21,22}$

In the 1980s, the Department of Health (DOH) focused attention on ways of targeting resources to meet the needs of the disadvantaged. In general practice this resulted in the development of a deprivation indicator ${ }^{23}$ that would measure morbidity and use of GP services, and that could be used as a guide to resource allocation in primary care. ${ }^{24}$

The burden of poverty in parts of inner London, together with the mobility of population and, in some areas, a relatively high proportion of elderly, singlehanded GPs who worked from poor premises and did not function as members of a primary care team, lead to the publication of the Acheson Report on Primary Care in London. ${ }^{25}$ This report put forward a large number of proposals aimed at improving the situation but they were largely ignored, one exception being the deprivation allowance that was later included in the 1990 contract for GPs.

\section{PRESCRIBING}

The number and cost of prescriptions dispensed through the Family Practitioner Services in the 1980s rose from 374 million prescriptions in 1980 to nearly 413 million in 1987, despite prescription charges trebling. Expansion of the prescription charge exemption scheme, which increased the proportion of free prescriptions from $70 \%$ in 1980 to $76 \%$ in 1987 offset the charge increases to some extent, although there is evidence that the increase in prescriptions would have been higher had there been no price increases. ${ }^{26}$

Generic prescribing also increased significantly in the 1980 s from $20 \%$ of all prescription medicines in 1980 to $39 \%$ in 1987, with the main increase occurring after $1984 .{ }^{26}$ The introduction of a 'limited list' of prescribable drugs in 1985 caused concern amongst many GPs because it was seen as an infringement on clinical freedom, but its effect on patient care was imperceptible. GPs now receive quarterly reports on their prescribing costs and how they relate to the national and local averages. This 'PACT' (prescribing analysis and cost) information permits GPs to undertake self audit of prescribing.

\section{DEPUTISING SERVICES}

One of the responses that GPs had made to the extension of their working week and the intensification of clinical activity was to reduce their on-call commitment, either by sharing it with a larger pool of local colleagues, or by sub-contracting it to commercial deputising agencies, or both. Between the middle and the end of the 1980 s the proportion of the working week spent on-call had fallen from $32.4 \%$ to $29.7 \%$, whilst the percentage of patient contacts made by commercial deputising services had increased from $8.7 \%$ to $11 \%$. $^{5}$ Twothirds of GPs used practice rotas for all or some on-call periods, and up to $30 \%$ collaborated with neighbouring practices for some on-call duties. ${ }^{13}$ By $198946 \%$ of night calls were made by deputising services ${ }^{27}$ and nearly a third of GPs reported no personal, regular commitment to their practice's night cover. ${ }^{13}$

Practice rotas for out-of-hours work were found to be popular with doctors and acceptable to patients, but as yet there has been no evaluation of the acceptability and clinical quality of collaborative, multi-practice rotas. ${ }^{13}$ Some of the deputising services were organised as doctors co-operatives, but the majority were commercial organisations, mostly situated in cities or large town where, typically, $70-80 \%$ of GPs made use of them. ${ }^{28}$ Although many GPs using commercial deputising services were satisfied with the quality of care provided, there was controversy within the profession about the qualifications of deputising doctors, their clinical standards and the effect of such services on demand for night calls. ${ }^{13}$ For example, one study found that patients visited by doctors from deputising services were uncertain of the identity and origin of these and were less satisfied with their consultations than with contacts with their own GPs, except for the over $60 \mathrm{~s} .{ }^{29}$ The professional debate spilled over into the political domain, and as a result of public criticism of care provided by deputising services there emerged a code of conduct which limited their use and gave greater responsibility for their regulation to Family Practitioner Committees. ${ }^{30}$ 
COMPUTERISATION

In 1987 only $10 \%$ of practices used computers for any aspect of practice activity, but by 1989 this had increased to $28 \%{ }^{31}$ By the late 1980 s around 40 different computer systems were on the market for GPs in England and Wales, ${ }^{32}$ all containing a database holding demographic information and some enabling the user to record details of consultations, risk factors, social and medical problems and diagnosis. Many were used for primarily for repeat prescribing and for practice administration, but all systems available had call and recall facilities for screening and immunisation, allowing GPs with this new technology to have an enhanced public health function.

REFERRALS TO SPECIALISTS

It is hardly surprising that referrals from GPs to specialists should become a controversial topic, since the boundaries of GPs' responsibilities seemed to be widening whilst the scope of specialist medicine itself enlarged. By the end of the decade there were nearly $\mathbf{4 0}$ million out-patient appointments made in NHS hospitals, between 60 and $80 \%$ of them originating from general practice, depending on speciality. ${ }^{33}$ The apparent 20 -fold variation in referral rates between doctors attracted the attention of the $\mathrm{DOH}$, which announced an intention to monitor and feed back referral rates to GPs in the 1987 White paper, Promoting better health. Default rates averaging $20 \%$ and reaching $40 \%$ for ENT referrals were noted in one study, ${ }^{34}$ whilst another showed that $25 \%$ of patients attending a medical out-patient clinic in one city also had appointments with other clinics for the same problem, ${ }^{35}$ each suggesting that there was scope for greater efficiency in providing specialist out-patient services.

A large-scale study of reasons for referral showed that a third were for investigation or diagnosis, a third for specific treatments or operations, and less than one in 20 for reassurance of patient or doctor. ${ }^{33}$ An overview of referral patterns suggested that referral appeared to be linked to the availability of specialists, not to local need, ${ }^{36}$ and the apparent wide variation in referral rates between GPs was shown to be a consequence of small numbers studied over short periods. ${ }^{37}$ Interpretation of research about referrals proved difficult, ${ }^{38}$ making characterisation of 'high referrers' problematic - were they bad doctors avoiding work within their competence, or good doctors identifying unmet need and recruiting specialist support appropriately?

The response from general practice to the debate about referrals was positive, and strategies for rationalising referrals, involving audit and the development of management protocols by GPs and consultants, ${ }^{33,39}$ were to become conventional wisdom in the $\mathrm{DOH}$ within a few years.

\section{Nursing and general practice}

A survey of community nurses in England and Wales in 1980 found that the vast majority regarded themselves as members of a 'primary health care team' and rated their contact with doctors as 'good' or 'very good.40 Close cooperation between GPs and district nurses or health visitors seems to be extending to other, more specialised, community nurses. ${ }^{41}$ Practice nurses directly employed by GPs constituted less than $10 \%$ of community nurses and the opportunities to expand their numbers were not taken, at least during the early part of the decade. ${ }^{42}$ However, this changed substantially later in the $1980 \mathrm{~s}$, with a $60 \%$ rise in numbers of whole time equivalent nurses working in practice, to 9000 by $1990^{2}$ and an extension of their role to incorporate chronic disease management and some preventive care. ${ }^{43}$

The Cumberledge Report argued that community nurses should work on a geographically defined 'patch' basis, but despite the small size and limited expansion of practice nursing, Government proposals emphasized the practicebased rather than patch-based organisation. However, the issue of which model to follow remained undecided through the 1980 s, particularly in the inner cities where well-organised local groups of nurses may offer a better service than those general practices with limited staffing who may not have practice nurses. ${ }^{42}$

One response to these conflicts in approach has been the importation from the US of the idea of 'nurse practitioners' ${ }^{40}$ Initially intended in the US as substitutes for doctors, particularly in deprived areas, nurse practitioners have been seen here as independent nursing professionals working within primary care teams, and pilot projects involving nurse practitioners have been undertaken in several areas. ${ }^{44}$ Given that a majority of GPs feel that they lack time to concentrate on patients with needs beyond their specific skills, ${ }^{45}$ and that a randomised trials of nurse versus GP care favoured the nurses, ${ }^{46}$ further extension of the 'nurse practitioner' role seems likely. 


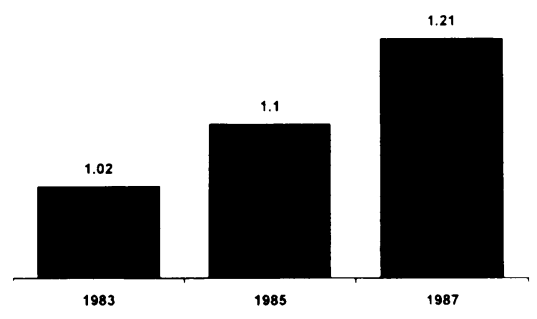

Figure 4 Average number of support staff per GP principal, 1983-7.
PRIMARY HEALTHCARE TEAMS

Before 1 April 1990, each GP could claim back from the Family Practitioner Committee $70 \%$ of the wage of up to two whole-time-equivalent ancillary staff. These ancillary workers could be receptionists, filing clerks, nurses, managers or computer operators. Although there was some increase in the numbers of ancillary staff employed during the 1980s (figure 4), most GPs did not use up their staff quota until the very end of the decade, when contractual reform was imminent and the need to re-configure practice organisation had become unavoidable. Even then the staff ratio only reached $1.8 .^{2}$

Primary healthcare teams were promoted by the Harding Report, ${ }^{46}$ but only a few interdependent multidisciplinary teams with a common purpose and responsibility developed. ${ }^{47}$ Because shared premises and the opportunity to meet informally but frequently are known to facilitate collaboration, ${ }^{48}$ team approaches to primary care were expected to develop as health centres were created, but there was virtually no growth in the proportion of GPs working from health centres in the $1980 \mathrm{~s}$, which remained at just over $25^{\circ}{ }_{0} .^{2}$

\section{INVOLVING THE PATIENT}

The World Health Organisation approach to primary healthcare emphasises the role of community participation and health promotion. Although some general practices have formed their own patient participation groups, the numbers are small and a considerable number have failed to survive because they lacked a clear role or depended on the activities of a few enthusiasts. ${ }^{48}$ Reviewing the very limited development of patient participation, Tudor Hart ${ }^{49}$ proposes that special interest groups aimed at particular problems, eg, hypertension, diabetes or asthma, might be more productive.

A consumerist approach to user involvement in general practice is more common, but no less problematic than the institutional approach of patient participation. The 1980s was the decade in which patients' wants underwent fundamental reappraisal. Explanation, understanding and emotional support were added to competent clinical care, courtesy and adequate information about illness as the desirable qualities of GPs, although the new desires varied widely in the population and were not always explicitly formulated in consultations. ${ }^{50}$ The scope for mutual misunderstanding, even in the lengthening consultations of the 1980 s, was well demonstrated by a three-practice study of 1500 consultations that showed that doctors perceived patients to be less ill than the people themselves did, whilst doctors focused on listening, supporting and giving advice to patients whose preferences, overall, were for prescribing, reassuring and referral. ${ }^{51}$ Increasing public dissatisfaction with appointments systems, out-ofhours visits and the telephone accessibility of $\mathrm{GPs}^{52}$ seemed related to the growth of group practices, which provided less personal care, especially to young people who were infrequently ill. ${ }^{53}$

Individually the changes in general practice described above were manageable. Together they created the stresses and strains of increasing workload, increasing uncertainty about roles, and increasing patient demand, and they appeared increasingly difficult to manage. This became most apparent as government policy sought to portray primary care as the foundation of the changing NHS, with much clinical work previously done in hospitals being transferred into the community. The effect of the internal market and cash limits on London's teaching hospitals precipitated a crisis in the city's primary care network when unrealistic expectations of change in primary care were fostered by the King's Fund $^{54}$ and echoed in the Tomlinson report. ${ }^{55}$

Professional opinion sought but did not find solutions to the problems generated by modernisation. The Royal College of General Practitioners continued its strategy of developing the discipline across a broad spectrum of activities, and fostered the ideas of peer review of quality of care, but failed to develop a package of reforms that could convince both the bulk of the profession and the government. Perhaps this is not surprising given the Royal College's foundation on the idea of personal, continuing care - features of general practice that were being undermined by modernisation.

A more coherent perspective emerges around the idea of anticipatory care, or population-based practice. Essentially a combination of epidemiology and traditional patient-centred care, the anticipatory care model in its pure form failed to attract the attention of more than a small minority of GPs, even amongst the new entrants. The lack of popularity may be because the anticipatory care model demands even more work and effort from doctors in the community, most of whom felt overburdened already, and also because its population orientation does not correspond to the realities of GP attitudes, in particular the attachment to individual patient care. However, some of its features were to influence government thinking in the early 1990s, and therefore had an impact on general practice. 
IMMINENT REFORM

The DOH could also utilise the peculiarities of the independent contractor status of GPs to produce a reform package to overcome the obstacles to further modernisation. The independent contractor status has seemed mysterious to many people, but is easy to understand if viewed as a form of public sector franchising. Franchising is an economic system in which a central organisation lends its trading name and logistic support to locally owned outlets whose proprietors take the financial risks of trading. ${ }^{56}$ Thus, the DOH acts as a franchisor, getting a network of primary care outlets (general practices) at low cost and minimal risk, staffed by a committed and relatively stable professional workforce with extensive knowledge of both local populations and local medical and social resources. GPs, as franchisees, get protection against risk through cost-rent schemes that subsidise the building or conversion of premises, reimbursement of staff wages and rent, predictable and reliable cash flows, NHS superannuation and other forms of financial support, together with some assistance in practice management, local autonomy and everyday control of activity, and profits subject only to schedule $\mathrm{D}$ taxation.

Franchising can be a form of organisation in which success is cloned rapidly at limited cost to the central management, which may be one reason why the government sought through the 1991 NHS reform to shift hospitals and community services onto a franchise basis, in the shape of Trusts. However, the natural history of franchising has features that GPs did not appear to understand before the beginning of the 1990s. ${ }^{56}$

To ensure that products or services are of standard quality, franchisors seek increasing control over their franchisees, especially when the outlet network enlarges and becomes more complex, as happened to general practice in the 1980s. Unilateral modification of contracts by franchisors then occurs, and the independence of the franchisee is eroded by increasingly specific contractual obligations, so that a point can sometimes be reached where the franchisee has all the responsibilities of an employee but none of the rights. In its later stages franchising can become a launch strategy for a new industry, allowing the rapid development of services which become too complex and too costly for local entrepreneurs to buy into and manage, with the result that the franchisor imposes its own management structure.

1 Department of Health. Primary health care - an agenda for discussion. Cmnd 9771. London: HMSO, 1986.

2 Pereira Gray D. Facts and figures about general practice. RCGP Members Reference Book. London: RCGP, 1991.

3 Health and personal social services statistics for England. London: HMSO, 1990.

4 Bosanquet N, Leese B. Family doctors and economic incentives. Aldershot: Dartmouth, 1989.

5 Doctors and Dentists Review Body. General medical practitioners workload survey 1989-90. London: Department of Health, 1991.

6 Marsh GN. General practice participation in the 6 Marsh GN. General practice participation in the Northern Region in 1983. BMF 1985; 290: 973.
7 Bull MJV. General practice obstetrics .. is there Bull MJV. General practice obst

8 Jewell D, Smith L. Is there a future for general practitioner obstetrics? RCGP Members Reference Book, London: RCGP, 1990; p 239.

9 Frischer M. Trends in morbidity and general practitioners' workload for middle-aged and elderly people from 1956 to 1982 . F Pub Health Med 1991; 13: 198-203.

10 Milner PC, Nichol JP, Williams BT. Variation in demand for accident and emergency departments in England 1974-1985. F Epidemiol Comments in England 1974-1985. F
munity Health 1988; 42: 274-8.

11 Central Statistical Office. Social Trends 23. London: HMSO, 1993.

12 Williams BT, Dixon RA, Nicholl JP. Provision of first contact care out-of-hours in four urban of first contact care out-of-hours in four urban
areas in England. BMF 1985; 291: 1689-92.

13 Hallum L. Primary medical are outside normal working hours: review of published work. $B M \mathcal{F}$ 1994; 308: 249-53

14 Williams BT. Night visits in general practice. $B M F$ 1993; 306: 734-5.

15 Iliffe S, Haines AP. Developments in British General Practice. Family Med 1989; 21: 169-70 175-6, 229-30.

16 Department of Health. Report of the Community Nursing Review: neighbourhood nursing - a focus for care. London: HMSO, 1986.

17 Hart JT. The inverse care law. Lancet 1971; 1: 405-12.

18 Yuen $P$, Balarjan R. Unemployment and patterns of consultation with the general practiterns of consultation with the $\mathrm{g}$
tioner. $B M \mathcal{F} 1989 ; 298: 1212-4$.

19 Balarjan R, Yuen P, Soni Raleigh V. Ethnic differences in general practitioner consultations. differences in general practio
$B M \mathcal{F} 1989 ; 299: 958-60$
20 Epidemiology \& Public Health Research Unit Health of children in single mother families. University of Surrey, Surrey; 1989.

21 Livingstone AE, Jewell JA, Robson J. Twentyfour hour care in inner cities: two years out of hours workload in east London general practice. $B M \mathcal{F}$ 1989; 299: 368-70.

22 Beale N, Nethercott $S$. The nature of unemploy ment morbidity: 1 Recognition. If $R$ Coll Gen Practit 1988; 38: 197-9.

23 Jarman $B$. Identification of underprivileged areas. BMf 1983; 286: 1705-9.

24 Curtis SE. Use of survey data and small area statistics to assess the link between individual statistics to assess the link between individual Epidemiol Community Health 1990; 44: 62-8.

25 London Health Planning Consortium. Primary health care in inner London - report of study group. London, 1981

26 Applelsy J. Prescription medicines. Health Ser f 1989; 99: 859.

27 Health Departments of Great Britain. General practice in the National Health Service. The 1990 contract. 1989.

28 Wilkin D, Hallam L, Leavey R. Anatomy of urban general practice. London: Tavistock, 1987.

29 Bollam MJ, McCarthy M, Modell M. Patients assessments of out of hours care in general assessments of out of hours care
practice. $B M \mathcal{F}$ 1988; 296: 829-32.

30 Griffith B, Iliffe S, Rayner G. Banking on sickness: commercial medicine in Britain and the USA. London: Lawrence \& Wishart, 1987.

31 NHS Management Executive. Computers in general practice 1993. Leeds: Department of Health, 1993.

32 Daniels A, Coulter A. How to choose a general practice computing system: comparison of commercial packages. $B M Y$ 1988: 297: 838-40.

33 Coulter A, Noone A, Goldacre M. Genera practitioners referrals to specialist outpatien clinics. 1. Why general practitioners refer patients to specialist outpatient clinics. 1989; 299: 304-6.

34 McGlade KJ, Bradley T, Murphy GJJ, Lundy GPP. Referrals to hospital by general practitioners: a study of compliance and communicationers: a study of compliance

35 Somanta A, Haider Y, Roffe C. An audit of patients attending a general medical follow-up patients attending a general medical foll
clinic. $\mathcal{F} R$ Coll Physic 1991; 25: 33-5.

36 Rowland MO, Morris R. Are referrals by general practitioners influenced by the availability of consultants? $B M F$ 1988; 297: 599-600.
37 Moore AT, Roland MO. How much variation in referral rates among general practitioners is due to chance? BMF 1989; 298: 500-2.

38 Roland MO. General practitioner referral rates. $B M \mathcal{F}$ 1988; 297: 437-8.

39 Emanuel J, Walther N. Referrals from general practice to hospital outpatient departments: a strategy for improvement. $B M \mathcal{F}$ 1989; 299: $722-4$.

40 Long AF, Mercer G. Health manpower: planning, production and management. London: 1987.

41 Dunnell L, Dobs J. Nurses working in the community. London: OPCS, HMSO, 1982.

42 Cumberlege J. Cumberlege on Cumberlege. Health Service 1986; 96: 621.

43 Jewell $D$, Turton P. What's happening to practice nursing? BMF 1994; 308: 735-6.

44 Stilwell B. The nurse practitioner at work: Primary care. Nursing Times 1982; 78: 1799-1803.

45 Bowling A. Delegation in general practice: a study of doctors and nurses. London: Tavistock, 1981.

46 Harding Report. The primary health care team. London: DHSS, 1981.

47 Bowling $A$. Which tasks can a community nurse take over? Nursing Times 1985; 81: 46-7.

48 Mann RG. Why patient participation group stop functioning: general practitioners' viewstop functioning: general practi

49 Hart JT. A new kind of doctor. London: Merlin Press, 1988 .

50 Armstrong D. What do patients want? $B M \mathcal{J}$ 1991; 303: 261-2.

51 Martin E, Russell D, Goodwin S, Chapman R North $M$, Sheridan $P$. Why patients consult and what happens when they do. $B M{ }^{\prime}$ 1991; 303: 289-92.

52 Allen D, Leavy R, Marks B. Survey of patient satisfaction with access to general practitioners. f $R$ Coll Gen Pract 1988; 38: 163-5.

53 Freeman GK, Richards SC. How much personal care in four group practices? $B M \mathcal{F} 1990$; 301: $1028-30$.

54 Kings Fund. London's health care 2010: changing the future of services in the capital, London: the future of services
Kings Fund, 1992.

55 Tomlinson B. Report of the enquiry into London's Tomlinson B. Report of the enquiry into London's Health services, medical
London: HMSO, 1992.

56 Stanworth J, Smith B. Franchising for the small business. Oxford: Blackwell, 1991. 